\title{
MENTAL HEALTH TREATMENT PREFERENCES OF OLDER AND YOUNGER PRIMARY CARE PATIENTS*
}

\author{
JULIE LOEBACH WETHERELL, Ph.D. \\ University of California, San Diego, and \\ VA San Diego Healthcare System \\ ROBERT M. KAPLAN, PH.D. \\ GENE KALLENBERG, M.D. \\ University of California, San Diego \\ TIMOTHY R. DRESSELHAUS, M.D., M.P.H. \\ University of California, San Diego, and \\ VA San Diego Healthcare System \\ WILLIAM J. SIEBER, PH.D. \\ University of California, San Diego \\ ARIEL J. LANG, PH.D. \\ University of California, San Diego, and \\ VA San Diego Healthcare System
}

\begin{abstract}
Objective: To compare mental health treatment history and preferences in older and younger primary care patients. Method: We surveyed 77 older $(60+)$ and 312 younger adult primary care patients from four outpatient medical clinics about their mental health treatment history and preferences. Results: Older adults were less likely than younger adults to report a history of
\end{abstract}

*Dr. Wetherell's research is funded by the National Institute of Mental Health, grant No. MH67643. Dr. Lang's research is funded by the National Institute of Mental Health, grant No. MH63152. 
mental health treatment ( $29 \%$ vs. $51 \%)$ or to be currently receiving treatment $(11 \%$ vs. $23 \%)$. They were also less likely to indicate that they currently desire help with emotional problems ( $25 \%$ vs. $50 \%)$. Older adults were more likely to hold a belief in self-reliance that could limit their willingness to accept treatment for mental health problems, although they were less likely than younger adults to identify other barriers to treatment. Older adults reported that they were less likely to attend programs in primary care targeting mental health issues (counseling, stress management) than younger adults, although they were as willing as younger adults to attend programs targeting physical health issues (healthy living class, fitness program). Age remained a significant predictor of mental health treatment history and preferences even after controlling for other demographic variables. Conclusion: These results suggest that older adults in the primary care setting may be less willing to accept mental health services than younger adults. Results further suggest that perceived barriers may differ for older and younger patients, which may indicate the need for age-specific educational messages and services targeted to older adults in primary care.

(Int'l. J. Psychiatry in Medicine 2004;34:219-233)

Key Words: patient preferences, mental health services, aged, primary health care

\section{INTRODUCTION}

Between 2000 and 2030, the number of older Americans is expected to double, from 35 million to 70.3 million individuals, or $20 \%$ of the U.S. population [1]. Experts have commented on the looming crisis in geriatric mental health care, with need likely to outstrip growth in the number of professionals trained to provide such services to older adults [2]. Although the prevalence of psychopathology in later life is substantial, with rates estimated at $1 \%$ to $4 \%$ for major depression and approximately $10 \%$ for anxiety disorders [3, 4], older adults underutilize the services of mental health providers [5-7]. Primary care providers often fail to recognize and treat mental health problems in older patients and are less likely to refer older adults to specialty mental health care [8-11]. Other barriers to service utilization include Medicare reimbursement policies and age bias on the part of mental health providers [12-14]. Although only approximately half of depressed older adults follow through on referrals to specialty mental health care [15], relatively few investigations have examined age differences in the mental health treatment preferences of patients themselves.

Understanding age differences in mental health treatment preferences is important in order to design interventions to optimize utilization among both younger and older adults. For example, older adults may benefit from educational interventions to increase recognition of need and facilitate entry into appropriate services, and services themselves could be targeted toward the preferences of older 
and younger adults. Findings summarized below suggest that age differences in preferences exist, but not enough information is currently available to help primary care or mental health providers design such educational interventions or develop and market age-appropriate services.

Data from a national Healthcare for Communities household telephone survey indicated that older adults with and without psychiatric disorders were less likely to perceive a need for mental health care than comparable younger adults [9]. Older adults were also less likely to receive mental health treatment than middleaged adults, even after controlling for lower rates of psychiatric disorders, and less likely than adults in any other age group to receive outpatient specialty mental health care. Benzodiazepine use, which is potentially hazardous in older adults, was the only mental health service category that increased with age (from $2.8 \%$ in young adults to $12.5 \%$ in older adults).

Only $57 \%$ of respondents in a telephone survey of older Michigan residents indicated that they would seek mental health services if needed [16]. People over the age of 65 in this study were significantly more likely than younger adults to report a preference for receiving mental health services from their primary care doctor $(65 \%$ vs. 53\%) and significantly less likely to seek services from a psychologist (4\% vs. 12.5\%). Older and younger adults did not differ in their reported willingness to seek services from a psychiatrist (14\% vs. 12.5\%).

Areán and her colleagues surveyed 183 older primary care patients on their preferences for mental health services [17]. Seventy-nine percent of the sample indicated that they would be willing to use some type of mental health services. More patients $(61 \%)$ indicated that they would be willing to speak with their primary care physician about mental health problems than with a nurse $(44 \%)$ or social worker $(44 \%)$. More patients endorsed a willingness to accept individual therapy (71\%) than group therapy $(34 \%)$ or psychoeducation classes on depression $(30 \%)$, stress $(34 \%)$, medical illness $(46 \%)$, or late-life problems (34\%).

With respect to specific type of treatment preferred for depression, one small study of 20 older adults found that behavior therapy was rated as more acceptable than medication as a treatment for depression [18]. Older adults in another study rated a form of behavior therapy as more acceptable and credible than pharmacotherapy for depression, and cognitive and psychodynamic therapies were rated equally acceptable and as credible as medications [19]. In a group of 200 older primary care patients in Canada, both cognitive therapy and bibliotherapy were rated as more acceptable than antidepressant medication for mild to moderate depression [20]. Cognitive therapy was rated as more acceptable than either bibliotherapy or medication for severe depression. Ratings did not differ based on level of respondents' depressive symptoms.

To our knowledge, the present study is the first to compare mental health treatment preferences of older and younger patients in the primary care setting. We collected data from patients in multiple settings, including both VA and 
university-affiliated primary care clinics. Moreover, we included a wider range of mental health preference topics than have been surveyed in previous studies. We examined whether older adults were less likely to report a history of treatment for emotional problems than younger adults, whether their preferences were different with respect to type of treatment or modality, perceived barriers to mental health service use, and likelihood of attending various types of psychosocial programs offered in the primary care setting.

\section{METHOD}

\section{Participants}

Trained research assistants recruited participants from the waiting rooms of four outpatient medical clinics, three affiliated with the University of California, San Diego $(n \mathrm{~s}=110,106$, and 102; total $75 \%)$, and one affiliated with the VA San Diego Healthcare System $(n=104 ; 25 \%)$. Respondents included 77 patients over the age of 60 and 312 patients between the ages of 18 and 59 (the other 33 patients did not indicate their age). Refusal rates were not available from every patient approached in the clinics but were estimated at approximately $40 \%$.

\section{Informed Consent}

Procedures for this study complied with ethical standards set by the UCSD Human Research Protections Program and the VA San Diego Healthcare System. All participants signed informed consent documents after receiving a complete description of the study.

\section{Procedures}

Participants were asked to fill out a short set of questionnaires in the waiting room on the day that they were recruited for the study, for which they were compensated \$10. These included background and health information. All participants were also asked to take home a set of questionnaires to complete and mail back. This battery included information on mental health treatment preferences. Participants were typically allowed to check all that apply for preference items. Participants received $\$ 20$ for completing this information. A total of 275 participants $(65 \%)$ mailed back the second set of questionnaires, $73 \%$ of the VA patients and $63 \%$ of patients from the three UCSD clinics; this difference just failed to reach statistical significance, $\chi^{2}(1, N=422)=$ $3.81, p<.06$.

The number of participants reporting valid responses to both age and mental health treatment preference questions ranged from 389 (out of 422, or 92\%) for questions about the likelihood of attending psychosocial programs in primary care, to $250(59 \%)$ for preferences about type and modality of treatment, to 
217 (51\%) for perceived barriers to treatment. Because there was no way to interpolate missing data from existing responses, the effective sample size varies from analysis to analysis.

\section{Analyses}

Data analyses were performed using SPSS release 11.5 for Windows. Group comparisons were made using univariate chi-square tests for categorical data and analysis of variance and Student's $t$-tests for continuous variables. For each comparison in which significant age differences were found, multivariate regression analyses were performed to determine whether age was a significant predictor after controlling for demographic variables. In each regression model, the demographic variables gender, ethnicity (coded as Caucasian vs. not Caucasian), education, income, and type of clinic (VA vs. UCSD) were entered in the first block, with age category entered in the second block.

\section{RESULTS}

Demographic information broken down by clinic is presented in Table 1 . There were significant differences across clinics in age, gender ratio, ethnicity, education, and income. Specifically, patients recruited from the VA tended to be male, older, and with lower incomes than patients recruited from the other three sites. Comparing participants by age across clinics, adults over the age of 60 were disproportionately male, $68 \%$ vs. $46 \%, \chi^{2}(d f=1)=11.72, p=.001$, and Caucasian, $66 \%$ vs. $49 \%, \chi^{2}(d f=1)=7.59, p=.006$, than younger adults. Older and younger adults also differed significantly in marital status, $\chi^{2}(d f=4)=28.52, p<.001$, primarily because older adults were less likely to have never married ( $7 \%$ vs. $39 \%)$. There were no significant age differences in education or income.

Table 2 presents age comparisons of mental health treatment history. Older adults were significantly less likely than younger adults to report a history of mental health treatment, although among those who had received treatment there were no differences in the types of treatments received (typically medications and individual therapy). Age was a significant predictor of treatment history even after controlling for gender, ethnicity, education, income, and type of clinic, $F$ change $(1,254)=12.51, p<.001$. Older adults were less likely to be currently receiving mental health services, even after controlling for demographic variables, $F$ change $(1,248)=7.20, p=.008$, and fewer older adults than younger adults indicated a current desire for mental health services after controlling for demographics, $F$ change $(1,243)=11.59, p<.001$.

With respect to preferences for types and modalities of treatment (Table 3), younger adults were more likely than older adults to prefer skills training (as in cognitive or behavioral therapies), even after controlling for demographic 


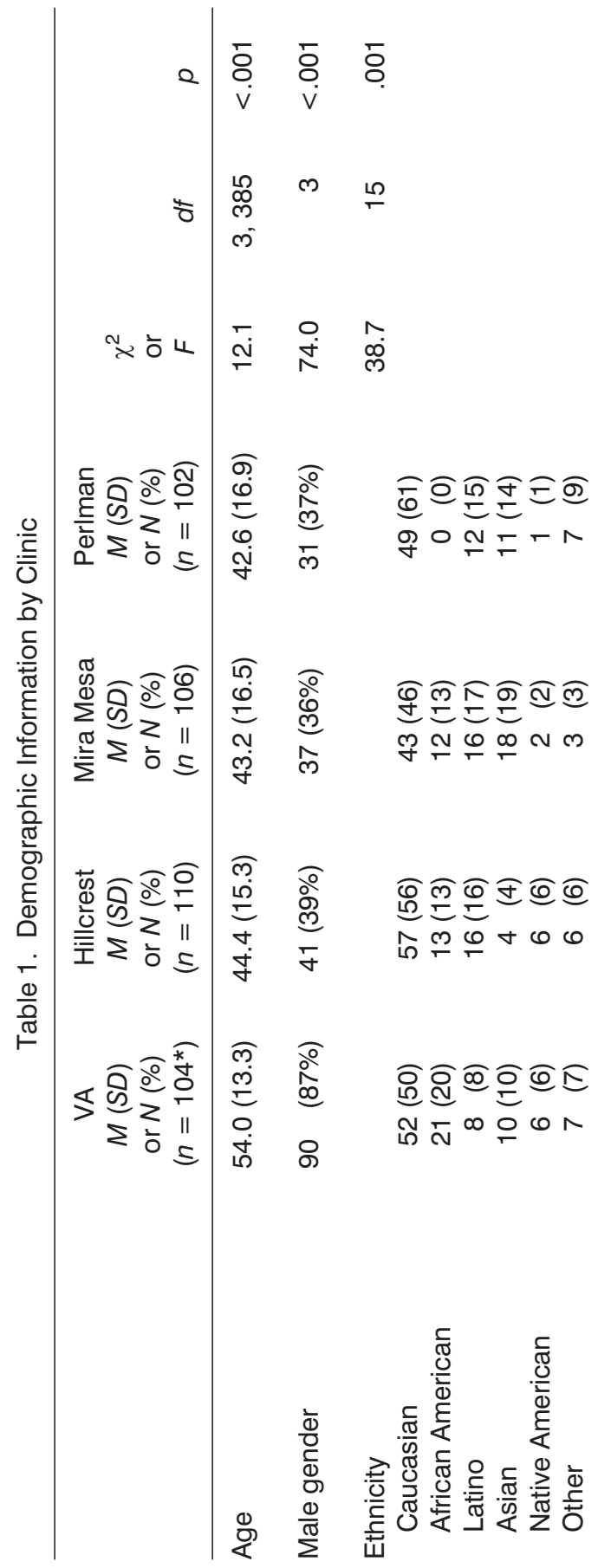


AGE DIFFERENCES IN TREATMENT PREFERENCES / 225

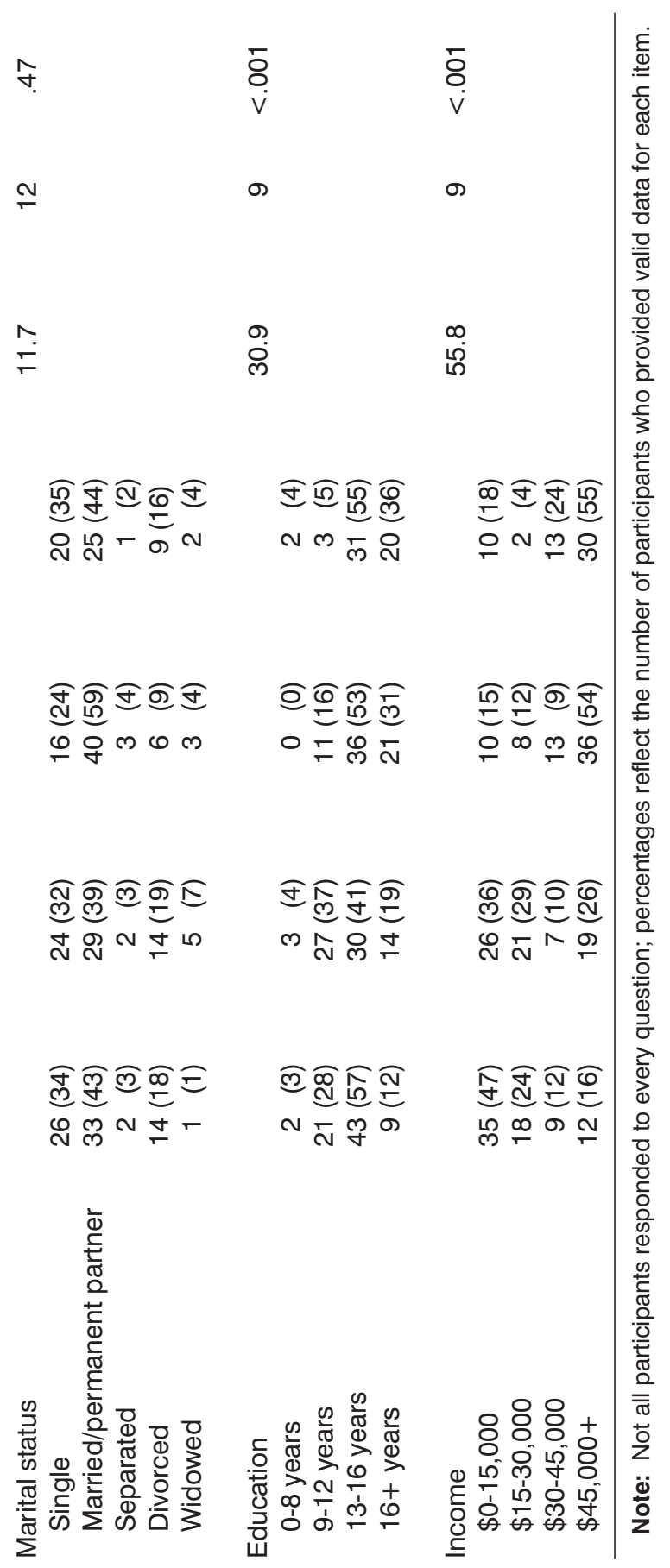


Table 2. Mental Health Treatment History in Younger and Older Primary Care Patients

\begin{tabular}{|c|c|c|c|c|}
\hline & $\begin{array}{c}\text { Younger } \\
\text { adults } \\
\text { (age < } 60 \\
N(\%) \\
(n=312) *\end{array}$ & $\begin{array}{c}\text { Older } \\
\text { adults } \\
\text { (age } \geq 60 \\
N(\%) \\
(n=77)\end{array}$ & $\chi^{2}$ & $p$ \\
\hline $\begin{array}{l}\text { History of treatment for emotional } \\
\text { problems }\end{array}$ & 105 (51\%) & 17 (29\%) & 8.70 & .003 \\
\hline Medications $^{a}$ & $82(76)$ & $13(77)$ & 0.00 & .96 \\
\hline Individual therapy ${ }^{a}$ & $79(74)$ & $12(71)$ & 0.08 & .78 \\
\hline Group counselinga & $31(29)$ & $8(47)$ & 2.23 & .14 \\
\hline Other ${ }^{a}$ & 7 (7) & $1(6)$ & 0.01 & .92 \\
\hline $\begin{array}{l}\text { Current treatment for emotional } \\
\text { problems }\end{array}$ & $47(23)$ & $6(11)$ & 4.25 & .04 \\
\hline $\begin{array}{l}\text { Currently desire treatment for } \\
\text { emotional problems }\end{array}$ & $102(50)$ & $13(25)$ & 11.24 & .001 \\
\hline
\end{tabular}

variables, $F$ change $(1,235)=4.41, p=.04$. The two most popular types of treatment among older adults were those involving greater insight and understanding (as in psychodynamic approaches) and talking (as in supportive therapy). Smaller proportions of patients in both age categories indicated a preference for medications, help with relationships, or help solving problems. There were no age differences in preferences among different modalities of treatment or in estimates of the length of time it would take to produce a treatment response. Most patients in both age groups preferred individual counseling to group therapy or medications, and most had a realistic expectation that some benefits of treatment should be expected within one month. With respect to barriers, the proportion of older adults who indicated that mental health treatment would take too much time did not differ from younger adults after controlling for demographic variables, $F$ change $(1,204)=2.66, p=.11$. Older adults were much less likely to identify other barriers to treatment, $F$ change $(1,204)=16.31, p<.001$, and were much more likely to endorse the statement that "I can work it out on my own," $F$ change $(1,204)=13.95, p<.001$, than younger adults. 
Table 3. Mental Health Treatment Preferences and Perceived Barriers in Younger and Older Primary Care Patients

\begin{tabular}{|c|c|c|c|c|}
\hline & $\begin{array}{c}\text { Younger } \\
\text { adults } \\
N(\%) \\
(n=312) *\end{array}$ & $\begin{array}{c}\text { Older } \\
\text { adults } \\
N(\%) \\
(n=77)\end{array}$ & $\chi^{2}$ & $p$ \\
\hline \multicolumn{5}{|l|}{ Preferred type of treatment ${ }^{a}$} \\
\hline Understanding/insight & $62(32)$ & $23(41)$ & 1.55 & .21 \\
\hline Talking & $45(23)$ & $17(30)$ & 1.15 & .28 \\
\hline Skills training & $65(34)$ & $10(18)$ & 5.16 & .02 \\
\hline Help with relationships & 24 (12) & $6(11)$ & 0.12 & .73 \\
\hline Medications & $20(10)$ & $6(11)$ & 0.01 & .94 \\
\hline Help solving problems & $19(10)$ & $5(9)$ & 0.04 & .84 \\
\hline Other & $14(7)$ & $3(5)$ & 0.25 & .62 \\
\hline \multicolumn{5}{|l|}{ Preferred modality ${ }^{a}$} \\
\hline Individual therapy & $140(72)$ & $36(64)$ & 1.30 & .26 \\
\hline Class or group & $31(16)$ & $10(18)$ & 0.11 & .74 \\
\hline Medications & $29(15)$ & $7(13)$ & 0.21 & .65 \\
\hline Other & $12(6)$ & $4(7)$ & 0.07 & .80 \\
\hline Time to response & & & 1.52 & .68 \\
\hline 1 week & $52(26)$ & $10(19)$ & & \\
\hline 1 month & $101(50)$ & $26(50)$ & & \\
\hline 6 months & $36(18)$ & $12(23)$ & & \\
\hline 1 year & $12(6)$ & $4(8)$ & & \\
\hline \multicolumn{5}{|l|}{ Perceived barriers $^{a}$} \\
\hline "I can work it out on my own" & $42(25)$ & $26(54)$ & 14.93 & $<.001$ \\
\hline Hassle & $38(23)$ & $12(25)$ & 0.13 & .72 \\
\hline "I'm not the type" & $32(19)$ & $12(25)$ & 0.85 & .36 \\
\hline l'd be too embarrassed & $25(15)$ & $7(15)$ & 0.00 & .97 \\
\hline Takes too much time & $40(24)$ & $5(10)$ & 3.99 & .046 \\
\hline Wouldn't help & $19(11)$ & $4(8)$ & 0.31 & .58 \\
\hline Other barrier & $56(33)$ & 4 (8) & 11.50 & .001 \\
\hline Total number of barriers & $1.47(1.00)$ & $1.46(0.90)$ & 0.10 & .92 \\
\hline \multicolumn{5}{|c|}{ Likely to attend programs in primary care ${ }^{a}$} \\
\hline Fitness & $168(54)$ & $33(43)$ & 2.99 & .08 \\
\hline Healthy living & $121(39)$ & $25(33)$ & 1.05 & .31 \\
\hline Stress management & $116(37)$ & $12(16)$ & 13.05 & $<.001$ \\
\hline Counseling & $103(33)$ & $7(9)$ & 17.43 & $<.001$ \\
\hline
\end{tabular}

${ }^{a}$ Respondents could select more than one option, so percentages do not add to 100 .

Note: Not all participants responded to every question; percentages reflect the number of participants who provided valid data for each item. 
When presented with four hypothetical treatment programs to be offered within their primary care clinic_-counseling, stress management, a healthy living class, and a fitness program - a significantly smaller proportion of older adults than younger adults indicated that they were likely to attend counseling or stress management, even after controlling for demographic variables, $F$ change $(1,257)=14.57, p<.001$, and $F$ change $(1,257)=6.38, p<.001$, respectively. There were no age differences in likelihood of attending the healthy living class or fitness program.

\section{DISCUSSION}

In this study of mental health treatment preferences in primary care, older adults were less likely than younger adults to report a history of or current participation in mental health treatment. They were also less likely to indicate that they currently desire help with emotional problems. Age was a significant predictor of mental health treatment history and some preferences and perceived barriers, even after controlling for demographic variables such as gender, ethnicity, education, income, and type of clinic (VA vs. UCSD).

Strikingly, participants of all ages reported a stronger preference for psychotherapy than for medications, even though medications were the most commonly used type of treatment among those who reported receiving treatment in the past. This finding contrasts with previous studies suggesting that approximately $30 \%$ of older primary care patients prefer to be treated with psychotherapy rather than with medications [21]. On the one hand, this finding, in combination with the finding that patients prefer individual therapy to group treatment, poses a challenge to the need to provide cost- and time-efficient mental health services. On the other hand, the fact that most patients believe that some improvement should be noticeable within a month supports the possibility of offering very brief individual psychotherapy in the primary care setting.

Older adults seemed to hold a preference for psychodynamic or supportive therapies relative to skills-based treatments such as cognitive-behavioral therapy. Given that cognitive and behavioral therapies have typically demonstrated stronger empirical support than alternative approaches, particularly for anxiety disorders, these findings suggest that more attention should be paid to educational messages about the content and efficacy of certain types of treatments in order to aid in dissemination efforts.

In terms of barriers, older adults were more likely than younger adults to hold a belief in self-reliance that could limit their willingness to accept treatment for mental health problems, although they were less likely than younger adults to identify other barriers to treatment. Older adults reported that they were less likely to attend programs in primary care targeting mental health issues than younger adults, although they were as willing as younger adults to attend programs targeting physical health issues. Overall, these results suggest that older adults in 
the primary care setting may be less willing to accept traditional mental health services than younger adults.

There are several alternative explanations for why older adults would use fewer mental health services than younger adults. We cannot assume that the need for mental health services is constant across the lifespan. Life stresses are different at different phases of life. Younger adults are more likely to have stresses at work, marital or partner conflict, role conflict, and stresses associated with parenting. Older adults are more likely to face stresses associated with chronic illness and loss of partners $[22,23]$. The experiences may not be equivalent. Studies of healthrelated quality of life in older adults using the Medical Outcomes Study 36-Item Short Form (SF-36) show that the mental health components systematically rise with age [24]. These results suggest that mental health may indeed improve as the population ages.

A second alternative explanation is that older adults might get different feedback from their primary care physicians than younger adults. In older adults, common symptoms of depression such as loss of appetite, sleep disturbance, or fatigue are often attributed to physical diagnoses associated with older people. The same symptoms, when reported by younger adults, might be attributed to depressed mood.

A third explanation for our results is that older adults, through greater life experience, may have gained a sense of self-efficacy for problem solving. Thus, they may be more inclined to endorse items such as "I can work it out on my own" or feel greater confidence in managing stress.

Because older adults underutilize specialty mental health services, their apparent reluctance, relative to younger adults, to accept mental health treatment in the primary care setting poses a challenge to appropriate diagnosis and treatment. Educational messages to improve understanding of mental health problems and treatment may help to reduce stigma and improve older adults' willingness to accept mental health services. Focusing on health rather than mental health issues (e.g., "Coping with late-life medical problems," "Healthy living for seniors") may encourage more participation by older adults in primary care. Messages that emphasize the compatibility of such programs with the value of self-reliance (e.g., "Help yourself to better health") may also facilitate acceptance by potential participants. Finally, better integration between primary care providers, who have a relationship with the patient but may not have the skills or resources to provide optimal mental health services, and mental health providers may help bridge the gap between need and utilization.

Several recent investigations have examined the utility of a collaborative care model in providing mental health treatment (specifically, treatment for depression) to older patients in primary care $[25,26]$. The fact that these programs typically offer individual sessions with a depression care specialist (usually a nurse) and a choice between medications and very brief psychotherapy may explain their success in terms of both patient adherence [27] and outcomes. Thus 
far, such programs have not been widely implemented outside of the research context, although they appear to hold promise for the delivery of mental health services to older adults in the primary care setting.

Other investigations have found promising results for exercise interventions in depressed older adults [28-31]. Findings from the present study suggest that such interventions may be an appealing option, particularly for older adults who resist traditional mental health services such as counseling or stress management classes. Developing ways to disseminate and test the effectiveness of such programs in primary care settings should be an important research and clinical priority.

The present study has several important limitations. One major limitation is the fact that older patients were more likely to come from the VA clinic than from the UCSD clinics. Older veterans may not be comparable to other medical clinic patients. In addition to being disproportionately male, they may be more likely to hold values that are incompatible with acceptance of mental health services, such as the importance of "keeping a stiff upper lip" or "not airing one's dirty laundry." They may also have different medical comorbidities that make them less representative of older primary care patients in general. Additional research on age differences in mental health treatment preferences is needed in other settings, particularly with economically disadvantaged and minority patients in the public health sector. In this study, however, site was not a significant predictor of service use or preferences.

A second limitation of the present study is the amount of missing data. Additionally, approximately $40 \%$ of patients initially approached to participate in the study refused. The relatively high rates of refusal and missing data make it difficult to determine the representativeness of this sample with respect to the clinic populations, let alone the generalizability of these results to patients in other outpatient medical settings. Specifically, study responders may have been less resistant to the idea of mental health treatment than nonresponders, which could potentially have biased the results of this investigation.

A third limitation is that our study assumes that the older sample and the younger sample are representative of their respective age groups. However, we do not have clear evidence that members of different age categories, sampled from the same clinics, are equivalent. Although there were no differences by education or income, the younger sample was significantly less likely to have never married. This may be a concern because never married status is associated with greater need for mental health services [32]. Further, the older sample was disproportionately male, while in the general population women have a higher probability than men of surviving to old age [33]. Thus, we encourage other investigators to replicate these results in larger and more heterogeneous populations.

The present study, however, is one of the first investigations of age differences in mental health treatment preferences in primary care patients. Moreover, the 
ethnic diversity of the sample represents a significant strength of this investigation. The findings are generally consistent with other research suggesting that older adults are more hesitant than younger adults to accept mental health treatment, even when such treatment is available in the primary care setting. Because most mental health care for older adults is provided in primary care, it is our hope that this study will spur the discourse and investigation necessary to improve access to mental health care for our increasing aged population.

\section{REFERENCES}

1. U.S. Census Bureau. National Population Projections, available at http://www.census.gov/population/www/projections/natsumT3.html.

2. Jeste DV, Alexopoulos GS, Bartels SJ, Cummings JL, Gallo JJ, Gottlieb GL, Halpain MC, Palmer BW, Patterson TL, Reynolds CF 3rd, Lebowitz BD. Consensus statement on the upcoming crisis in geriatric mental health: research agenda for the next 2 decades. Archives of General Psychiatry 1999;56:848-853.

3. Blazer DG. Depression in late life: review and commentary. Journals of Gerontology: Biological Sciences and Medical Sciences 2003;58A:249-265.

4. Beekman AT, Bremmer MA, Deeg DJ, van Balkom AJ, Smmit JH, de Beurs E, van Dyck R, van Tilburg W. Anxiety disorders in later life: A report from the Longitudinal Aging Study Amsterdam. International Journal of Geriatric Psychiatry 1998; 13:717-726.

5. Cooper-Patrick L, Crum RM, Ford DE. Characteristics of patients with major depression who received care in general medical and specialty mental health settings. Medical Care 1994;32:15-24.

6. Ware J Jr, Kosinski M, Keller SD. A 12-Item Short-Form Health Survey: construction of scales and preliminary tests of reliability and validity. Medical Care 1996;34:220-233.

7. Young AS, Klap R, Sherbourne CD, Wells KB. The quality of care for depressive and anxiety disorders in the United States. Archives of General Psychiatry 2001; 58:55-61.

8. Blanchard MR, Waterreus A, Mann AH. The effect of primary care nurse interventions upon older people screened as depressed. International Journal of Geriatric Psychiatry 1995; 10:289-298.

9. Klap R, Unroe KT, Unützer J. Caring for mental illness in the United States: A focus on older adults. American Journal of Geriatric Psychiatry 2003;11: 517-524.

10. Orrell M, Scurfield P, Cloke L, Renshaw J. The management of depression in older people in primary care: A survey of general practitioners. Ageing and Mental Health 2000;4:305-308.

11. Watts SC, Bhutani GE, Stout IH, Ducker GM, Cleator PJ, McGarry J, Day M. Mental health in older adult recipients of primary care services: Is depression the key issue? Identification, treatment, and the general practitioner. International Journal of Geriatric Psychiatry 2002;17:427-437.

12. Koenig HG, George LK, Schneider R. Mental health care for older adults in the year 2020: A dangerous and avoided topic. Gerontologist 1994;5:674-679. 
13. Lagana L, Shanks S. Mutual biases underlying the problematic relationship between older adults and mental health providers: any solution in sight? International Journal of Aging and Human Development 2002;55:271-295.

14. Mackenzie CS, Gekoski WL, Knox VJ. Do family physicians treat older patients with mental disorders differently from younger patients? Canadian Family Physician 1999;45:1219-1224.

15. Callahan CM, Hui SL, Nienaber NA, Musick BS, Tierney WM. Longitudinal study of depression and health services use among elderly primary care patients. Journal of the American Geriatrics Society 1994;42:833-838.

16. Mickus M, Colenda CC, Hogan AJ. Knowledge of mental health benefits and preferences for type of mental health providers among the general public. Psychiatric Services 2000;51:199-202.

17. Areán PA, Alvidrez J, Barrera A, Robinson GS, Hicks S. Would older patients use psychological services? Gerontologist 2002;52:392-398.

18. Lundervold D, Lewin LM. Older adults' acceptability of pharmacotherapy and behavior therapy for depression: Initial results. Journal of Applied Gerontology 1990;9:211-215.

19. Rokke PD, Scogin F. Depression treatment preferences in younger and older adults. Journal of Clinical Geropsychology 1995;1:243-257.

20. Landreville P, Landry J, Baillargeon L, Guérette A, Matteau E. Older adults' acceptance of psychological and pharmacological treatments for depression. Journals of Gerontology: Psychological Sciences 2001;56B:P285-P291.

21. Areán PA, Hegel MT, Reynolds CF III. Treating depression in older medical patients with psychotherapy. Journal of Clinical Geropsychology 2001;7:93-104.

22. Almeida DM, Wethington E, Kessler RC. The daily inventory of stressful events: An interview-based approach for measuring daily stressors. Assessment 2002;9:45-55.

23. Wethington E, Kessler RC. Employment, parental responsibility, and psychological distress: A longitudinal study of married women. Journal of Family Issues 1989; 10:527-546.

24. Ware JE, Kosinski M, Bayliss MS, McHorney CA, Rogers WH, Raczek A. Comparison of methods for the scoring and statistical analysis of SF-36 health profile and summary measures: Summary of results from the Medical Outcomes Study. Medical Care 1995;33(4 Suppl.):AS264-279.

25. Mulsant BH, Alexopoulos GS, Reynolds CF III. Treatment of depression in older primary care patients: The PROSPECT algorithm. International Journal of Geriatric Psychiatry 2001;16:585-592.

26. Unützer J, Katon W, Callahan CM, Williams JW Jr, Hunkeler E, Harpole L, Hoffing M, Della Penna RD, Noel PH, Lin EH, Areán PA, Hegel MT, Tang L, Belin TR, Oishi S, Langston C; IMPACT Investigators. Improving Mood-Promoting Access to Collaborative Treatment. Collaborative care management of late-life depression in the primary care setting: A randomized controlled trial. Journal of the American Medical Association 2002;288:2836-2845.

27. Wetherell JL, Unützer J. Adherence to treatment for geriatric depression and anxiety. CNS Spectrums 2003;8(Suppl. 3):48-59.

28. Blumenthal JA, Babyak MA, Moore KA, Craighead WE, Herman S, Khatri P, Waugh R, Napolitano MA, Forman LM, Appelbaum M, Doraiswamy PM, Krishnan KR. Effects of exercise training on older patients with major depression. Archives of Internal Medicine 1999;159:2349-2356. 
29. Singh NA, Clements KM, Singh MA. The efficacy of exercise as a long-term antidepressant in elderly subjects: A randomized, controlled trial. Journals of Gerontology: Medical Sciences 2001;56:M497-M504.

30. Mather AS, Rodriguez C, Guthrie MF, McHarg AM, Reid IC, McMurdo ME. Effects of exercise on depressive symptoms in older adults with poorly responsive depressive disorder: Randomized controlled trial. British Journal of Psychiatry 2002; 180:411-415.

31. Penninx BW, Rejeski WJ, Pandya J, Miller ME, Di Bari M, Applegate WB, Pahor M. Exercise and depressive symptoms: A comparison of aerobic and resistance exercise effects on emotional and physical function in older persons with high and low depressive symptomatology. Journals of Gerontology: Psychological Sciences 2002;57: P124-P132.

32. Kaplan RM, Kronick RG. Mortality status and longevity in the United States population. Annals of Behavioral Medicine 2003;25:S117.

33. Oechsli FW. A population model based on a life table that includes marriage and parity. Theoretical Population Biology 1975;7:227-245.

Direct reprint requests to:

Ariel J. Lang, Ph.D.

VA Outpatient Clinic (MC116A4Z)

8810 Rio San Diego Dr.

San Diego, CA 92108

e-mail: ajlang@ucsd.edu 